\title{
Biomechanical effects of metastasis in the osteoporotic lumbar spine: A Finite Element Analysis
}

\author{
Giuseppe Salvatore ${ }^{1}$, Alessandra Berton ${ }^{1}$, Hugo Giambini ${ }^{2}$, Mauro Ciuffreda', Pino Florio ${ }^{1}$, \\ Umile Giuseppe Longo ${ }^{1 *}$ (D, Vincenzo Denaro ${ }^{1}$, Andrew Thoreson ${ }^{2}$ and Kai-Nan $\mathrm{An}^{2}$
}

\begin{abstract}
Background: Cancer patients are likely to undergo osteoporosis as consequence of hormone manipulation and/or chemotherapy. Little is known about possible increased risk of fracture in this population. The aim of this study was to describe the biomechanical effect of a metastatic lesion in an osteoporotic lumbar spine model.

Methods: A finite element model of two spinal motion segments (L3-L5) was extracted from a previously developed L3-Sacrum model and used to analyze the effect of metastasis size and bone mineral density (BMD) on Vertebral bulge (VB) and Vertebral height (VH). VB and VH represent respectively radial and axial displacement and they have been correlated to burst fracture. A total of 6 scenarios were evaluated combining three metastasis sizes (no metastasis, $15 \%$ and $30 \%$ of the vertebral body) and two BMD conditions (normal BMD and osteoporosis).

Results: $15 \%$ metastasis increased VB and VH by $178 \%$ and $248 \%$, respectively in normal BMD model; while VB and VH increased by $134 \%$ and $174 \%$ in osteoporotic model. 30\% metastasis increased VB and VH by $88 \%$ and 109\%, respectively, when compared to $15 \%$ metastasis in normal BMD model; while VB and $\mathrm{VH}$ increased by $59 \%$ and $74 \%$ in osteoporotic model.

Conclusion: A metastasis in the osteoporotic lumbar spine always leads to a higher risk of vertebral fracture. This risk increases with the size of the metastasis. Unexpectedly, an increment in metastasis size in the normal BMD spine produces a greater impact on vertebral stability compared to the osteoporotic spine.
\end{abstract}

Keywords: Metastasis, Vertebral fracture, Vertebroplasty, Osteoporosis, Finite element analysis, Lumbar spine

\section{Background}

The spine is the most common site for skeletal metastasis, with one third of all cancer patients developing metastases of the spine [1]. Because advancements in oncological treatments have improved patients' survival, the prevalence of spinal metastases is bound to increase [2]. Vertebral fractures caused by spine metastases result in pain, deformity, loss of mobility, and/or neurological complications, significantly affecting quality of life [3-5].

Many patients with metastases of the spine are likely to decrease their bone mineral density (BMD), leading to osteopenia or osteoporosis, as a consequence of

\footnotetext{
* Correspondence: g.longo@unicampus.it

1 Department of Orthopaedic and Trauma Surgery, Campus Bio-Medico

University, Via Alvaro del Portillo, 200, 00128 Trigoria, Rome, Italy

Full list of author information is available at the end of the article
}

hormone manipulation and/or chemotherapy [6], increasing the risk of vertebral fractures. Snyder et al. developed a computed tomography-based structural analysis (CTRA) method to predict fracture risk associated with osteolytic vertebral lesions [7]. Although highly sensitive and more specific than radiographs, validation studies are still ongoing. On the other hand, little is known about the increased risk of fracture in osteoporotic patients with metastatic lesions. Predictive tools, such as dual absorptiometry (DXA), quantitative computed tomography-based finite element analysis (QCT/FEA), biomechanical computed tomography-based FEA (BCT/ FEA), have been implemented to improve fracture risk assessment in osteoporotic patients, but they have not been considered for osteoporotic cancer patients [8-11]. 
Biomechanical studies investigating the risk of fracture in metastatic spines lack realistic models and are not ideal for parametric analyses [12]. Because cadaveric studies are performed with normal spines, simulated lytic defects are typically developed by removing a core of trabecular bone and penetrating the cortical structure [13-16]. Similarly, clinical studies, including retrospective reviews of patients, can hardly extrapolate the influence of every individual variable as the patients population is generally heterogeneous and uncontrolled multiple factors can influence the results [12]. On the other hand, finite element analysis, successful in predicting failure loads and fracture patterns for bone structures $[8,17-24]$, allows a parametric representation of complex geometric and material property distributions.

The aim of this study was to evaluate the biomechanical effects of a metastatic lesion in an osteoporotic model of the lumbar spine.

\section{Methods}

\section{Finite element model}

A finite element model of two spinal motion segments (L3-L5) was extracted from a previously developed and validated three-dimensional, nonlinear, ligamentous L3Sacrum model [25, 26] (Fig. 1). Development of the model is described in more details in the prior publication [25] and summarized here for convenience. The geometry and dimensions of the model were obtained from a high-resolution computed tomography scan (Siemens Helical CT Scanner, Siemens Corp., Munich, Germany $-0.293 \mathrm{~mm}$ in plane pixel size, $0.4 \mathrm{~mm}$ slice thickness) of a fresh, frozen human cadaveric spine specimen (male, 52 yrs. old). DICOM images were imported into Mimics image processing and editing software (Materialise US, Plymouth, MI USA) for segmentation. Since soft tissue was poorly visualized on CT scans, the discs were generated using the wrap function in 3-matic 4.2 (Materialise, Ann Arbor, MI, USA). Discs was modeled as a composite of a solid matrix with embedded fibers in concentric rings. The Nucleus pulposum was surrounded by seven annulus fibrosus lamellae, containing two evenly spaced layers of fibers oriented at approximately $\pm 30^{\circ}$ to the horizontal plane $[27,28]$. The fibers were defined using 3-D two-node truss elements. Collagenous fiber content varies from $23 \%$ in the outermost layer to $5 \%$ in the innermost layer $[29,30]$. Thus, the cross-sectional area of the truss elements was determined based on the annular layer volume and the number of elements to satisfy the fiber content distribution. The fiber thickness and stiffness increased in the radial direction. A "no compression" option was defined for the annulus fibrosus such that the elements resist tension only. The solid matrix of the annulus fibrosus was modeled as a neo-Hookean solid, while the nucleus pulposum was linearly elastic.

The finite element mesh was generated using HyperMesh 10.0 (Altair Engineering, Inc., Troy, MI, USA).

The model included the vertebral bodies consisting of a cortical shell, cancellous centrum, endplates and posterior elements. Intervertebral discs consisted of a nucleus pulposus, annulus ground substances, and annulus fibrosus (seven layers). All major ligaments were represented: (anterior longitudinal, posterior longitudinal, intertransverse, ligamentum flavum, interspinous, supraspinous, and capsular). The ligaments were modeled with 3-D two node truss elements and assigned nonlinear hypoelastic material properties, which allow axial stiffness to be a

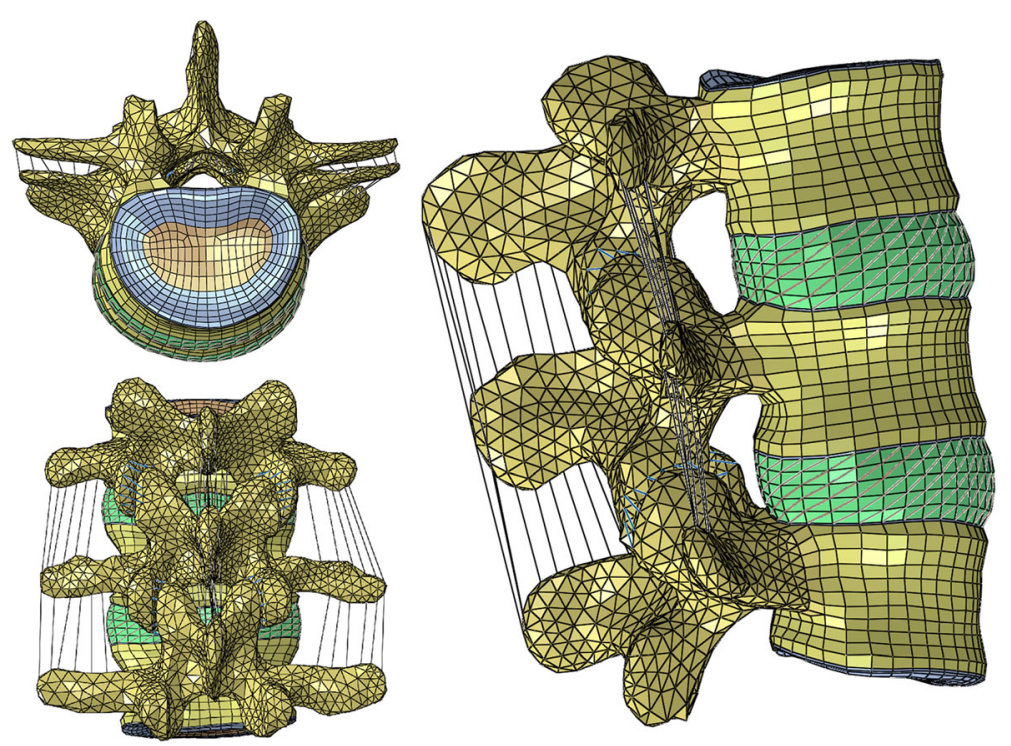

Fig. 1 Finite element model of two spinal motion segments (L3-L5) 
function of axial strain. At initially low strains the ligaments exhibit low stiffness, but as the strains increase the ligament stiffness increases. The crosssectional areas of each ligament were obtained from literature. All elements representing the ligaments were aligned in the anatomical fiber direction and unstressed at the unloaded state [28].

The metastasis was represented as a lytic bone lesion. Material properties for all structures are summarized in Table 1.

\section{Boundary conditions and loads}

Nodes at the lower surface of the L5 vertebra, corresponding to the endplate, were encastred and constrained from all three axes of rotation and translations. A reference node was placed $10 \mathrm{~mm}$ above the $\mathrm{L} 3$ vertebra and surface nodes from the vertebra and the reference node were selected to form rigid bodies and create a kinematic coupling. This constrain limited the motion of aforementioned nodes to the motion applied to the reference node [31]. An axial compressive load of $1200 \mathrm{~N}$ was applied to the superior reference node atop the L3 vertebra to represent upper body weight. This load corresponds to a compressive force on the lumbar

Table 1 Finite element model material properties

\begin{tabular}{lll}
\hline & Elastic Modulus (MPa) & Poisson's Ratio \\
\hline Vertebra & & \\
Cancellous Bone & 100 & 0.2 \\
Cortical Bone & 12,000 & 0.3 \\
Vertebral Bony Endplate & 4000 & 0.3 \\
Cartilage Endplate & 5 & 0.17 \\
Posterior Bone & 3500 & 0.25 \\
Intervertebral Disc & & \\
Nucleus Polposus & 1 & 0.49 \\
Annular Fibers & Neo-Hooke & \\
Annular Layers & Neo-Hooke & \\
Joint & & \\
Facet Joints & 3500 & 0.3 \\
Ligaments & & 0.3 \\
Anterior Longitudinal & $15.6-20.0$ & 0.3 \\
Posterior Longitudinal & $10.0-20.0$ & 0.3 \\
Intertransverse & $12-58.7$ & 0.3 \\
Ligamentum Flavum & $13.0-19.5$ & \\
Interspinous & $9.8-12.0$ & \\
Supraspinous & $8.8-15.0$ & \\
Capsular & $7.5-33.0$ & \\
Metastasis & & 0.3 \\
Lytic Bone Metastasis & 0.01 & \\
\hline
\end{tabular}

spine for an individual standing upright holding an $8.3 \mathrm{~kg}$ mass with outstretched arms [32].

\section{Parametric analyses}

A parametric analysis was performed varying metastasis size and BMD. Metastatic lesion was varied to represent $15 \%$ and $30 \%$ of the vertebral body volume by selecting elements at the central core of the L4 vertebral body. (Fig. 2). Osteoporosis was defined by a $66 \%$ reduction in the elastic moduli of all bony structures for the cancellous bone, and by $33 \%$ for the cortical shell, the endplates, and the posterior elements [33]. Soft tissue structures were left unchanged. A total of 6 scenarios were evaluated, as described in Table 2. Scenario 1 (Normal BMD - Metastasis size 0\%) was used as a baseline for comparison with other normal BMD conditions. Scenario 4 (Osteoporotic - Metastasis size 0\%) was used as baseline for comparison with other osteoporotic conditions.

\section{Outcomes variables}

Vertebral fracture risk was analyzed based on vertebral bulge (VB) and vertebral height (VH) outcomes [13]. Vertebral bulge, representing the maximum radial displacement at the transverse midline of the vertebral body, has been noted to correlate with load-induced spinal canal narrowing, vertebral cortex tensile hoop strains, and bone marrow pressurization [13]. Vertebral

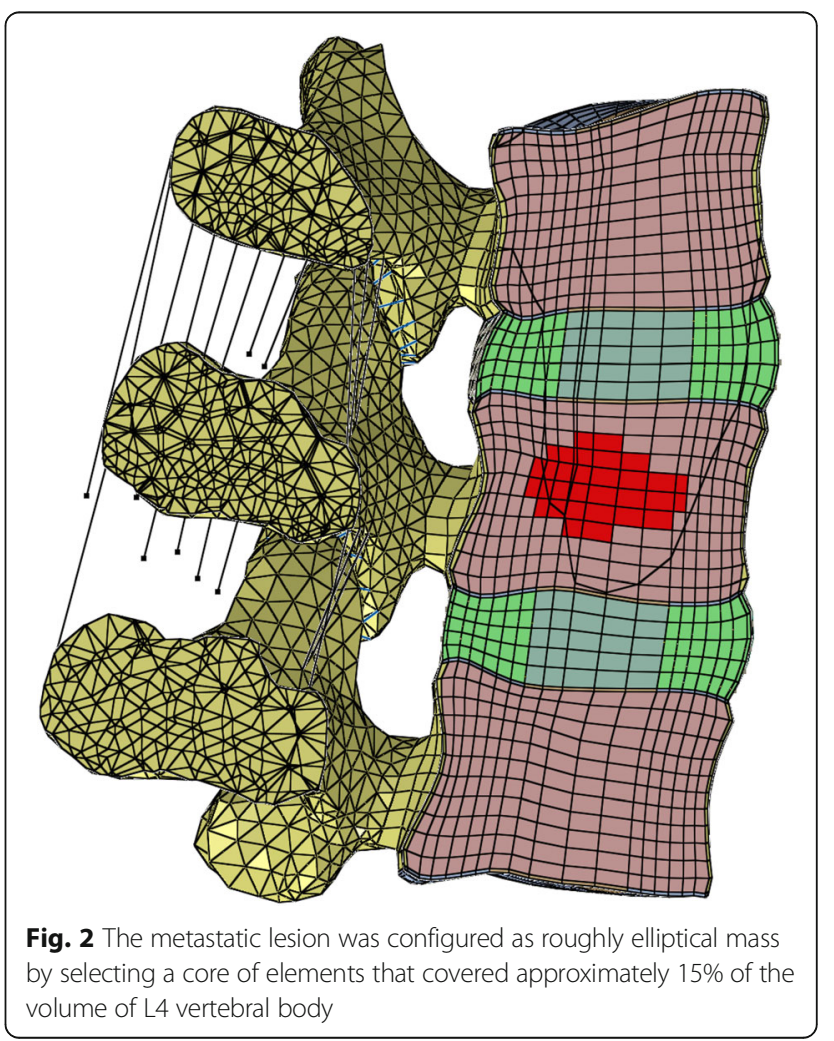


Table 2 Investigated scenarios

\begin{tabular}{lll}
\hline Scenario & BMD & Metastasis Size \\
\hline 1 & Normal & $0 \%$ \\
2 & Normal & $15 \%$ \\
3 & Normal & $30 \%$ \\
4 & Osteoporotic & $0 \%$ \\
5 & Osteoporotic & $15 \%$ \\
6 & Osteoporotic & $30 \%$ \\
\hline
\end{tabular}

Scenario 1 (Normal BMD - Metastasis size 0\%) and scenario 4 (Osteoporotic Metastasis size $0 \%$ ) were used as baseline
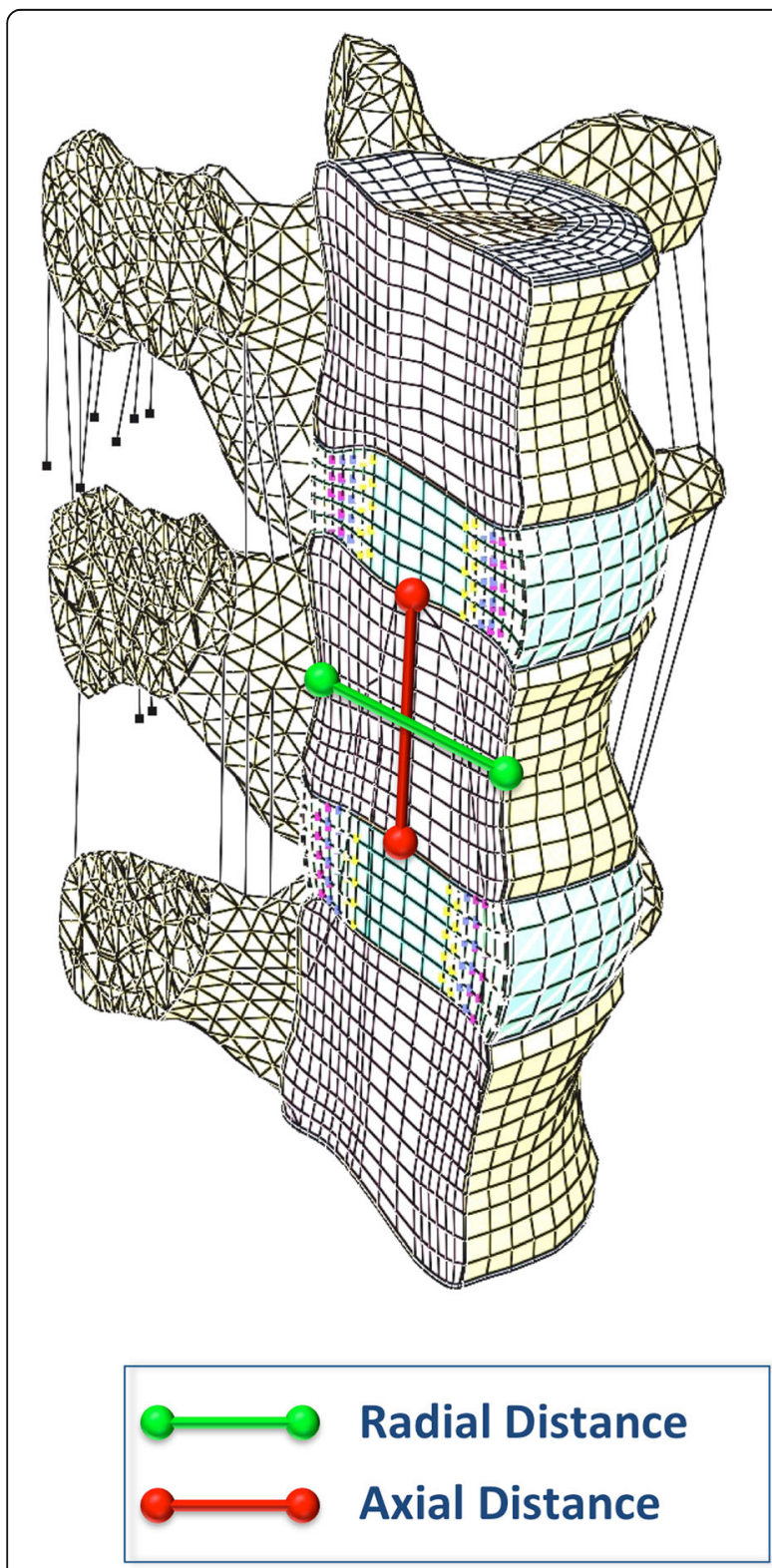

Fig. 3 Radial Distance (green line): distance between two standard nodes at the mid-height of $L 4$ on the sagittal plane. Axial Distance (red line): distance between two standard nodes at the center of the inferior and superior endplates of $L 4$ height, representing the maximum axial displacement of the endplates, characterizes the risk of endplate failure leading to subsequent burst fracture [13].

The distance between two standard nodes at the midheight of L4 on the sagittal plane was measured (Radial Distance, Fig. 3). VB was calculated as the difference between the Radial Distance before and after the axial compressive load was applied ( $\mathrm{VB}=$ Radial Distance after load - Radial Distance before load).

The distance between two standard nodes at the center of the inferior and superior endplates of L4 was measured (Axial Distance, Fig. 3). VH was calculated as the difference between the Axial Distance before and after the axial compressive load was applied $(\mathrm{VH}=$ Axial Distance before load - Axial Distance after load).

\section{Results}

Results for the simulations with metastasis were normalized to relative baseline scenarios of intact vertebra without metastasis (Scenario 1: VB $0.05 \mathrm{~mm}, \mathrm{VH} 0.15 \mathrm{~mm}$ and Scenario 4: VB $0.123 \mathrm{~mm}, \mathrm{VH} 0.417 \mathrm{~mm}$ ). In normal BMD scenarios, $15 \%$ metastasis increased VB by $178 \%$ $(0.139 \mathrm{~mm})$ and $\mathrm{VH}$ by $248 \%(0.522 \mathrm{~mm})$; while a $30 \%$ metastasis increased VB by $424 \%(0.262 \mathrm{~mm})$ and $\mathrm{VH}$ by $626 \%(1.09 \mathrm{~mm})$. A comparison of metastatic lesion size showed a $30 \%$ metastasis to increase VB by $88 \%$ $(0.139 \mathrm{~mm}$ vs $0.262 \mathrm{~mm})$ and $\mathrm{VH}$ by $109 \%$ (0.522 vs 1.09 ) when compared to a $15 \%$ metastasis. In osteoporotic scenarios, a $15 \%$ metastasis increased VB by $134 \%$ $(0.288 \mathrm{~mm})$ and $\mathrm{VH}$ by $174 \%(1.145 \mathrm{~mm})$; while a $30 \%$ metastasis increased VB by $272 \%(0.458 \mathrm{~mm})$ and $\mathrm{VH}$ by $479 \%(1.996 \mathrm{~mm})$. Comparing the two metastatic scenarios $(15 \%$ and $30 \%)$, VB increased by $59 \%$ ( 0.288 vs 0.458 ) and $\mathrm{VH}$ by $74 \%$ (1.145 vs 1.996$)$. When same metastasis size scenarios were compared, the osteoporotic spine had larger $\mathrm{VB}$ and $\mathrm{VH}$ values compared to normal BMD scenario. Results are summarized in Table 3 and Fig. 4.

\section{Discussion}

The purpose of this study was to describe the biomechanical effect of a metastatic lesion in an osteoporotic lumbar spine model in order to better understand the risk of vertebral fractures in this population. A finite element model of two spinal motion segments (L3-L5) was used to analyze the effect of metastasis size and osteoporosis on VB and VH. Results from the study showed osteoporosis can represent a risk of fracture

Table $3 \mathrm{VB}$ and VH for each scenario, absolute values

\begin{tabular}{lllll}
\hline BMD & Normal & \multicolumn{3}{l}{ Osteoporotic } \\
\hline Metastasis size & $15 \%$ & $30 \%$ & $15 \%$ & $30 \%$ \\
VB & 0.133 & 0.262 & 0.288 & 0.458 \\
VH & 0.522 & 1.09 & 1.145 & 1.996 \\
\hline
\end{tabular}




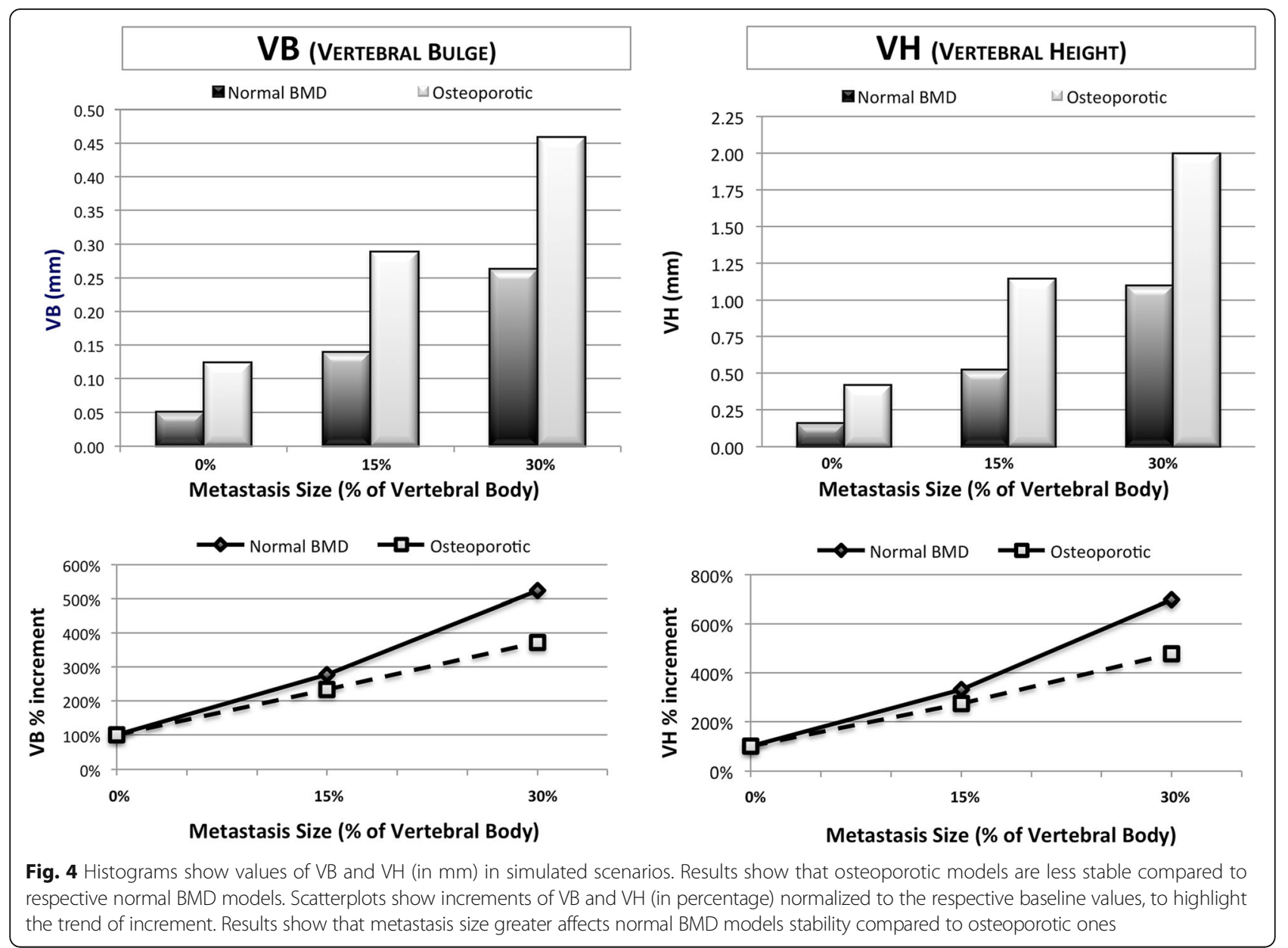

regardless of metastasis size compared to patients with normal BMD. Furthermore, an increase in metastasis size has a greater impact on the risk of fracture in patients with normal BMD compared to osteoporotic patients.

A previous study by Taneichi et al. [34] identified the following criteria of impending collapse: 1) 50-60\% involvement of the vertebral body with no destruction of other structures, or 25-30\% involvement with costovertebral joint destruction in the thoracic spine; and 2) $35-40 \%$ involvement of vertebral body, or $20-25 \%$ involvement with posterior elements destruction in thoracolumbar and lumbar spine. It is well known that the load bearing capacity of bone is influenced by the geometry, location, biological activity of the tumor, and the geometry and material properties of the host bone [34]. Several studies have investigated the risk of vertebral fracture in osteoporotic bones [35-45]. However, there is still a lack of knowledge relating the interactive and/or cumulative effect of metastatic cancer and osteoporosis [46, 47].

To the best of our knowledge, this is the first threedimensional, anatomical model of two spinal motion segments (L3-L5) that investigates a metastatic lesion in an osteoporotic spine. A previous study by Whyne et al., investigated the effects of tumor size, material properties and compressive loading rate on vertebral strength, using a two-dimensional, symmetric finite element model of the L1 vertebral body without posterior elements [48]. Two additional studies by Whyne et al. implemented a three-dimensional finite element model of the L1 vertebra including the posterior arch but no additional posterior elements were represented $[13,49]$. These studies showed tumor size to be the predominant contributor towards the risk of initiating a burst fracture, followed by the applied load magnitude and bone density. However, the biomechanical response, including stress distribution and geometrical changes, is more complex in a spine segment comprised of the vertebral bodies with posterior elements and soft tissues (intervertebral discs and ligamentous structures). The posterior elements, facet joints and ligaments share a substantial portion of the loads applied to the spine, stabilizing and preventing vertebral bulge [50]. Tschirat et al. developed a geometrical three-dimensional finite element model of a thoracic spine segment to understand the effects of vertebral level, geometry, and 
metastasis on the cortical shell $[51,52]$. The study demonstrated that upper thoracic vertebrae are at greater risk of burst fracture, and that kyphotic segments, ribcage and transcortical tumor provided lower risk of burst fracture initiation [52]. Moreover, the effect of multiple loading conditions on metastatically-involved thoracic spinal motion segment was investigated showing axial loading as the predominant load type leading to increased risk of burst fracture initiation [51]. However, the load distribution in the lumbar spine might differ from that observed in the thoracic spine due to the presence of the ribcage, vertebral size, lordotic angle, and articular facet angles. Our results showed osteoporosis to highly affect vertebral outcomes of the model. Previous studies have only modified trabecular bone material properties based on an assumed apparent density [13, 48, 49]. In order to obtain a reliable representation of an osteoporotic spine, the current model included changes in the material properties of the cortical shell, endplates and posterior elements.

This study has limitations. The L3-L5 finite element model was extracted from a previously developed and validated three-dimensional, nonlinear, ligamentous L3Sacrum model $[25,26]$. Prior validation of the L3Sacrum model allows considering results derived from the L3-L5 model as reasonable. However, the two spinal motion segment model cannot be considered as properly validated. The metastatic lesion was represented as an ellipsoid, and tumor shape can influence vertebral bulge and vertebral axial displacements [33, 41]. However, the ellipsoidal geometry is frequently used in finite element models of metastasis [13, 41, 49]. Second, only an axial compressive load of $1200 \mathrm{~N}$ was studied. However, this represents a compressive force on the lumbar spine for an individual standing upright holding an $8.3 \mathrm{~kg}$ mass with outstretched arms [32]. Lower loading regime should be studied in order to simulate daily life tasks of endstage cancer patients that can be translated to clinical practice. Third, additional motions or loads were not simulated. Tschirhart et al. [51] suggested focusing primarily on axial compressive loading rather than complex load/boundary conditions since it is the predominant load type leading to increased risk of burst fracture initiation of the thoracic spine and it is likely to be the same for the lumbar segment. Fourth, it could be argued that metastatic lesions are more common in the thoracic spine rather than in the lumbar spine. However, we aimed to evaluate the effect of axial loading without the influences of the ribs, which can contribute to reduce the effective axial loading applied on the vertebra. Therefore, we decided to study the lumbar spine segment. In future studies, we are planning to study localization of metastasis to the thoracic spine. Fifth, we only simulated a lytic metastasis. Blastic lesions are frequent and should be investigated in future studies.
However, it should be taken into account that, both lytic and blastic metastasis lead to a decrease in bone mineralization [46, 53]. Mineral content have been demonstrated to be strongly correlated with strength/stiffness [54-56]. Thus, the reason for fracture of a metastatic vertebra is related to poor bone quality, both in case of lytic and blastic metastasis. Finally, our parametric study was limited to metastasis size and bone mineral density. Future studies should evaluate metastasis location, vertebral level, pedicle involvement, metastasis type, and disc degeneration.

\section{Conclusions}

A metastasis in the osteoporotic lumbar spine always leads to a higher risk of vertebral fracture. This risk increases with the size of the metastasis. Unexpectedly, an increment in metastasis size in the normal BMD spine produces a greater impact on vertebral stability compared to the osteoporotic spine.

\section{Abbreviations}

BCT/FEA: Biomechanical computed tomography-based FEA; BMD: Bone mineral density; CTRA: Computed tomography-based structural analysis; DXA: Dual absorptiometry; QCT/FEA: Quantitative computed tomographybased finite element analysis; VB: Vertebral bulge; VH: Vertebral height

\section{Acknowledgements}

No one else contributed towards the article except for the authors. None of the authors received funding.

No one else contributed materials essential for the study except for the authors.

\section{Funding}

The authors declare that they have no conflict of interest and no funding source.

\section{Availability of data and materials}

Data will be shared for readers upon reasonable request.

\section{Authors' contributions}

GS and $A B$ wrote the manuscript, optimized the FEA model and performed the FEA simulations. $A B, M C$ and PF performed the data extraction and analysis, and draw figures and Tables. HG contributed to the creation and validation of the FEA model. UGL, VD, AT and KNA contributed to data interpretation and reviewed the manuscript. All authors read and approved the final manuscript.

\section{Ethics approval and consent to participate}

The frozen human cadaveric spine specimen was obtained from the Mayo Anatomical Bequest Program. Ethical approval was originally obtained and the donor gave consent for his body to be used for medical research.

\section{Consent for publication}

Not applicable.

\section{Competing interests}

$A B, U G L$ and $A T$ are members of the Editorial Board of BMC Musculoskeletal Disorders. The other authors declare that they have no competing interests.

\section{Publisher's Note}

Springer Nature remains neutral with regard to jurisdictional claims in published maps and institutional affiliations.

\section{Author details}

${ }^{1}$ Department of Orthopaedic and Trauma Surgery, Campus Bio-Medico University, Via Alvaro del Portillo, 200, 00128 Trigoria, Rome, Italy. 
²Biomechanics Laboratory, Division of Orthopaedic Research, Mayo Clinic, Rochester, MN, USA.

\section{Received: 2 March 2017 Accepted: 22 January 2018 Published online: 05 February 2018}

\section{References}

1. Aaron AD. The management of cancer metastatic to bone. JAMA : the journal of the American Medical Association. 1994;272(15):1206-9.

2. Ohmori K, Matsui $H$, Yasuda T, Kanamori M, Yudoh K, Seto H, Tsuji H. Evaluation of the prognosis of cancer patients with metastatic bone tumors based on serial bone scintigrams. Jpn J Clin Oncol. 1997;27(4):263-7.

3. Hortobagyi GN, Theriault RL, Lipton A, Porter L, Blayney D, Sinoff C, Wheeler $\mathrm{H}$, Simeone JF, Seaman JJ, Knight RD, et al. Long-term prevention of skeletal complications of metastatic breast cancer with pamidronate. Protocol 19 Aredia breast cancer study group. J Clin Oncol. 1998;16(6):2038-44.

4. Hortobagyi GN. The status of breast cancer management: challenges and opportunities. Breast Cancer Res Treat. 2002;75(Suppl 1):S61-5. discussion S57-69

5. Hipp JA, Springfield DS, Hayes WC. Predicting pathologic fracture risk in the management of metastatic bone defects. Clin Orthop Relat Res. 1995;312: 120-35

6. Mincey BA, Moraghan TJ, Perez EA. Prevention and treatment of osteoporosis in women with breast cancer. Mayo Clinic proceedings Mayo Clinic. 2000;75(8): 821-9.

7. Snyder BD, Cordio MA, Nazarian A, Kwak SD, Chang DJ, Entezari V, Zurakowski D. Parker LM. Noninvasive prediction of fracture risk in patients with metastatic cancer to the spine. Clin Cancer Res. 2009;15(24):7676-83.

8. Wang X, Sanyal A, Cawthon PM, Palermo L, Jekir M, Christensen J, Ensrud KE, Cummings SR, Orwoll E, Black DM, et al. Prediction of new clinical vertebral fractures in elderly men using finite element analysis of CT scans. J Bone Miner Res. 2012;27(4):808-16.

9. Morgan SL, Lopez-Ben R, Nunnally N, Burroughs L, Desmond R. Nonprogression of vertebral area or bone mineral content on DXA does not predict compression fractures. J Clin Densitom. 2006;9(3):261-4.

10. Shepherd JA, Schousboe JT, Broy SB, Engelke K, Leslie WD. Executive summary of the 2015 ISCD position development conference on advanced measures from DXA and QCT: fracture prediction beyond BMD. J Clin Densitom. 2015; 18(3):274-86.

11. Zysset P, Qin L, Lang T, Khosla S, Leslie WD, Shepherd JA, Schousboe JT, Engelke K. Clinical use of quantitative computed tomography-based finite element analysis of the hip and spine in the Management of Osteoporosis in adults: the 2015 ISCD official positions-part II. J Clin Densitom. 2015;18(3): 359-92.

12. Whyne CM. Biomechanics of metastatic disease in the vertebral column Neurol Res. 2014;36(6):493-501.

13. Whyne CM, Hu SS, Lotz JC. Burst fracture in the metastatically involved spine: development, validation, and parametric analysis of a three-dimensional poroelastic finite-element model. Spine. 2003;28(7):652-60.

14. Windhagen HJ, Hipp JA, Silva MJ, Lipson SJ, Hayes WC. Predicting failure of thoracic vertebrae with simulated and actual metastatic defects. Clin Orthop Relat Res. 1997;344:313-319.

15. Dimar JR 2nd, Voor MJ, Zhang YM, Glassman SD. A human cadaver model for determination of pathologic fracture threshold resulting from tumorous destruction of the vertebral body. Spine. 1998;23(11):1209-14

16. McGowan DP, Hipp JA, Takeuchi T, White AA 3rd, Hayes WC. Strength reductions from trabecular destruction within thoracic vertebrae. J Spinal Disord. 1993:6(2):130-136.

17. Huiskes R, Hollister SJ. From structure to process, from organ to cell: recent developments of FE-analysis in orthopaedic biomechanics. J Biomech Eng. 1993;115(4B):520-7.

18. Lotz JC, Cheal EJ, Hayes WC. Fracture prediction for the proximal femur using finite element models: part I-linear analysis. J Biomech Eng. 1991; 113(4):353-60

19. Matsuura Y, Giambini H, Ogawa Y, Fang Z, Thoreson AR, Yaszemski MJ, Lu L, An KN. Specimen-specific nonlinear finite element modeling to predict vertebrae fracture loads after vertebroplasty. Spine. 2014;39(22):E1291-6.

20. Morgan EF, Yeh OC, Keaveny TM. Damage in trabecular bone at small strains. Eur J Morphol. 2005:42(1-2):13-21.

21. Morgan EF, Bayraktar HH, Yeh OC, Majumdar S, Burghardt A, Keaveny TM. Contribution of inter-site variations in architecture to trabecular bone apparent yield strains. J Biomech. 2004;37(9):1413-20.
22. Morgan EF, Bayraktar HH, Keaveny TM. Trabecular bone modulus-density relationships depend on anatomic site. J Biomech. 2003;36(7):897-904.

23. Keaveny TM, Morgan EF, Niebur GL, Yeh OC. Biomechanics of trabecular bone. Annu Rev Biomed Eng. 2001:3:307-33.

24. Amin S, Kopperdhal DL, Melton L 3rd, Achenbach SJ, Therneau TM, Riggs BL, Keaveny TM, Khosla S. Association of hip strength estimates by finite-element analysis with fractures in women and men. J Bone Miner Res. 2011; 26(7):1593-600.

25. Ellingson AM, Shaw MN, Giambini H, An KN. Comparative role of disc degeneration and ligament failure on functional mechanics of the lumbar spine. Comput Methods Biomech Biomed Engin. 2015:1-10.

26. Viceconti M, Olsen S, Nolte LP, Burton K. Extracting clinically relevant data from finite element simulations. Clin Biomech. 2005:20(5):451-4.

27. Goel VK, Monroe BT, Gilbertson LG, Brinckmann P. Interlaminar shear stresses and laminae separation in a disc. Finite element analysis of the L3-L4 motion segment subjected to axial compressive loads. Spine. 1995;20(6):689-98.

28. White AAPM. Clinical biomechanics of the spine. 2nd ed. Philadelphia: JB Lippincott; 1990

29. Shirazi-Adl A, Ahmed AM, Shrivastava SC. A finite element study of a lumbar motion segment subjected to pure sagittal plane moments. J Biomech. 1986:19(4):331-50.

30. Schmidt H, Kettler A, Heuer F, Simon U, Claes L, Wilke HJ. Intradiscal pressure, shear strain, and fiber strain in the intervertebral disc under combined loading. Spine. 2007;32(7):748-55

31. Corp. DSS (ed.): Abaqus Analysis User's Manual. Providence, Rl.; 2008 a.

32. Schultz A, Andersson G, Ortengren R, Haderspeck K, Nachemson A. Loads on the lumbar spine. Validation of a biomechanical analysis by measurements of intradiscal pressures and myoelectric signals. J Bone Joint Surg Am. 1982; 64(5):713-20.

33. Polikeit A, Nolte LP, Ferguson SJ. The effect of cement augmentation on the load transfer in an osteoporotic functional spinal unit: finite-element analysis. Spine. 2003:28(10):991-6.

34. Taneichi H, Kaneda K, Takeda N, Abumi K, Satoh S. Risk factors and probability of vertebral body collapse in metastases of the thoracic and lumbar spine. Spine. 1997;22(3):239-45.

35. Longo UG, Loppini M, Denaro L, Maffulli N, Denaro V. Conservative management of patients with an osteoporotic vertebral fracture: a review of the literature. J Bone Joint Surg Br. 2012:94(2):152-7.

36. Longo UG, Loppini M, Denaro L, Maffulli N, Denaro V. Osteoporotic vertebral fractures: current concepts of consenvative care. Br Med Bull. 2012;102:171-89.

37. Denaro V, Longo UG, Denaro L. Vertebroplasty versus conservative treatment for vertebral fractures. Lancet. 2010;376(9758):2071. author reply 2071-2072

38. Longo UG, Denaro L, Campi S, Maffulli N, Denaro V. Upper cervical spine injuries: indications and limits of the conservative management in halo vest. A systematic review of efficacy and safety. Injury. 2010;41(11):1127-35.

39. Denaro L, Longo UG, Denaro V. Vertebroplasty and kyphoplasty: reasons for concern? Orthop Clin North Am. 2009:40(4):465-71. viii

40. Denaro V, Longo UG, Maffulli N, Denaro L. Vertebroplasty and kyphoplasty. Clin Cases Miner Bone Metab. 2009:6(2):125-30.

41. Tschirhart CE, Nagpurkar A, Whyne CM. Effects of tumor location, shape and surface serration on burst fracture risk in the metastatic spine. J Biomech. 2004;37(5):653-60

42. Longo UG, Denaro V. Spinal augmentation: what have we learnt? Lancet. 2009;373(9679):1947. author reply 1947-1948

43. Kopperdahl DL, Aspelund T, Hoffmann PF, Sigurdsson S, Siggeirsdottir K, Harris TB, Gudnason V, Keaveny TM. Assessment of incident spine and hip fractures in women and men using finite element analysis of $C T$ scans, J Bone Miner Res. 2014;29(3):570-80.

44. Anderson DE, Demissie S, Allaire BT, Bruno AG, Kopperdahl DL, Keaveny TM, Kiel DP, Bouxsein ML. The associations between QCT-based vertebral bone measurements and prevalent vertebral fractures depend on the spinal locations of both bone measurement and fracture. Osteoporos Int. 2014 25(2):559-66.

45. Fields AJ, Keaveny TM. Trabecular architecture and vertebral fragility in osteoporosis. Curr Osteoporos Rep. 2012;10(2):132-40.

46. Nazarian A, von Stechow D, Zurakowski D, Muller R, Snyder BD. Bone volume fraction explains the variation in strength and stiffness of cancellous bone affected by metastatic cancer and osteoporosis. Calcif Tissue Int. 2008;83(6):368-79.

47. Snyder BD, Piazza S, Edwards WT, Hayes WC. Role of trabecular morphology in the etiology of age-related vertebral fractures. Calcif Tissue Int. 1993; 53(Suppl 1):S14-22. 
48. Whyne CM, Hu SS, Lotz JC. Parametric finite element analysis of vertebral bodies affected by tumors. J Biomech. 2001;34(10):1317-24.

49. Whyne CM, Hu SS, Lotz JC. Biomechanically derived guideline equations for burst fracture risk prediction in the metastatically involved spine. J Spinal Disord Tech. 2003;16(2):180-5.

50. Whyne CM, Hu SS, Klisch S, Lotz JC. Effect of the pedicle and posterior arch on vertebral body strength predictions in finite element modeling. Spine. 1998;23(8):899-907.

51. Tschirhart CE, Finkelstein JA, Whyne CM. Metastatic burst fracture risk assessment based on complex loading of the thoracic spine. Ann Biomed Eng. 2006;34(3):494-505.

52. Tschirhart CE, Finkelstein JA, Whyne CM. Biomechanics of vertebral level, geometry, and transcortical tumors in the metastatic spine. J Biomech. 2007:40(1):46-54.

53. Sone T, Tamada T, Jo Y, Miyoshi H, Fukunaga M. Analysis of three-dimensional microarchitecture and degree of mineralization in bone metastases from prostate cancer using synchrotron microcomputed tomography. Bone. 2004;35(2):432-8.

54. Burr DB. The contribution of the organic matrix to bone's material properties. Bone. 2002;31(1):8-11.

55. Currey JD. The mechanical consequences of variation in the mineral content of bone. J Biomech. 1969;2(1):1-11.

56. Currey JD. The effect of porosity and mineral content on the Young's modulus of elasticity of compact bone. J Biomech. 1988;21(2):131-9.

\section{Submit your next manuscript to BioMed Central and we will help you at every step:}

- We accept pre-submission inquiries

- Our selector tool helps you to find the most relevant journal

- We provide round the clock customer support

- Convenient online submission

- Thorough peer review

- Inclusion in PubMed and all major indexing services

- Maximum visibility for your research

Submit your manuscript at www.biomedcentral.com/submit 